\title{
Erratum: Structural health monitoring of 3D frame structures using finite element modal analysis and genetic algorithm
}

\author{
S. Tiachacht ${ }^{1}$, A. Bouazzouni ${ }^{2}$, S. Khatir ${ }^{3}$, A. Behtani ${ }^{4}$, Y.-L.-M. Zhou ${ }^{5}$, M. Abdel Wahab ${ }^{6}$ \\ ${ }_{1,2,4}$ Laboratory of Mechanics, Structure and Energetics (LMSE), \\ Mouloud Mammeri University of Tizi-Ouzou, B.P.N ${ }^{\circ} 17$ RP, 15000, Algeria \\ ${ }^{3}$ Department of Electrical Energy, Systems and Automation, Faculty of Engineering and Architecture, \\ Ghent University, Ghent, Belgium \\ ${ }^{5}$ Department of Civil and Environmental Engineering, National University of Singapore, \\ 2 Engineering Drive 2, 117576, Singapore \\ ${ }^{6}$ Division of Computational Mechanics, Ton Duc Thang University, Ho Chi Minh City, Vietnam \\ ${ }^{6}$ Faculty of Civil Engineering, Ton Duc Thang University, Ho Chi Minh City, Vietnam \\ ${ }^{6}$ Soete Laboratory, Faculty of Engineering and Architecture, Ghent University, \\ Technologiepark Zwijnaarde 903, B-9052, Zwijnaarde, Belgium \\ ${ }^{6}$ Corresponding author \\ E-mail: ${ }^{1}$ tiachachtsamir@gmail.com, ${ }^{2}$ abouazzouni@yahoo.com, ${ }^{3}$ khatir_samir@hotmail.fr, \\ ${ }^{4}$ behtani2007@hotmail.com, ${ }^{5}$ zhouyunlai168168@gmail.com, ${ }^{6}$ magd.abdelwahab@tdt.edu.vn, \\ ${ }^{6}$ magd.abdelwahab@ugent.be
}

DOI https://doi.org/10.21595/jve.2018.19767

Check for updates

\section{Publisher's note regarding paper}

Tiachacht S., Bouazzouni A., Khatir S., Behtani A., Zhou Y.-L.-M., Wahab M. Abdel Structural health monitoring of 3D frame structures using finite element modal analysis and genetic algorithm. Journal of Vibroengineering, Vol. 20, Issue 1, 2018, p. 202-214, https://doi.org/10.21595/jve.2017.18571.

\section{The description of the correction}

The author's name was misspelled in the paper originally submitted and finally approved (after the acceptance) by the Authors.

Incorrect author's name:

Y.-L.-M. Zhou

Correct author's name:

Y.-L. Zhou 